\title{
Species identification of the psammophilous tenebrionid beetles Phaleria acuminata Küster, 1852 and Phaleria bimaculata (Linnaeus, 1767) from central Mediterranean beaches: geometric morphometrics and molecular insights from species to population level
}

\author{
Federico Marrone $\cdot$ Alan Deidun · Tiziana Curatolo • \\ Marco Arculeo $\cdot$ Sabrina Lo Brutto \\ Received: 12 June 2013/Revised: 18 September 2013/Accepted: 28 September 2013/Published online: 22 October 2013 \\ (c) Springer-Verlag Berlin Heidelberg 2013
}

\begin{abstract}
Dominating global arid environments, from desert to coastal dunes, most Tenebrionidae are highly specific in their habitat preferences and display limited dispersal potential, thus exhibiting a remarkable degree of regional genetic and morphological differentiation. The tenebrionid genus Phaleria is speciose and widely distributed, with $P$. acuminata and $P$. bimaculata having a wide Mediterranean distribution, with numerous morphological differentiations at population level, often described as different taxa of doubtful taxonomical significance. In order to investigate the variability of the central Mediterranean populations of $P$. bimaculata and $P$. acuminata and to compare the results obtained with different identification techniques, these species were sampled on sandy beaches in Sicily (southern Italy) and on circum-Sicilian and Maltese islands. Collected samples were studied through the application of geometric morphometrics and the sequencing of a fragment of the mitochondrial COII gene. Geometric morphometrics and molecular analyses gave congruent results, allowing a sound separation of the two species. At the population level, the two species showed different patterns. P. acuminata showed a remarkable morphological and molecular homogeneity throughout the sampled area. Conversely, two well-characterized subclades were detected within P. bimaculata, and within the
\end{abstract}

Communicated by A. Schmidt-Rhaesa.

F. Marrone $\cdot$ T. Curatolo $\cdot$ M. Arculeo $\cdot$ S. Lo Brutto $(\bowtie)$ Department STeBICeF, Sezione di Biologia animale e Antropologia Biologica, University of Palermo, via Archirafi 18, 90123 Palermo, Italy

e-mail: sabrina.lobrutto@unipa.it

A. Deidun

IOI-MOC, University of Malta, Msida MSD 2080, Malta two lineages, a low-to-absent inter-populations differentiation was observed, in spite of the physical isolation of the sampled sandy beaches and of their geographical distance. These two $P$. bimaculata lineages, hereby named "Tyrrhenian sub-clade" and "Southern sub-clade," might be compatible with the hypothesis of subspecific status already proposed for the populations from the Aeolian archipelago (as P. bimaculata marcuzzii Aliquò).

Keywords Sandy beaches - Phaleria spp. C Central Mediterranean - Species delimitation - Molecular systematics · Geometric morphometrics

\section{Introduction}

The Mediterranean Sea is a basin that, with its noteworthy environmental diversity along coastlines, can be considered "a great natural laboratory" where to measure and assess macroscopic and cryptic variability. The biocenoses inhabiting the coastal habitats are subject to various forms of environmental pressures, and their study is assuming greater importance. In the face of an increasing pressure due to anthropogenic activities and climate changes, there is an unrelenting search for reliable target species for assessing and monitoring biodiversity (e.g., Lo Brutto et al. 2011; Sarà et al. 2012); accordingly, a sound taxonomic identification of the target taxa, as well as information on their morphological and genetic diversity, is certainly necessary.

The coleopteran family Tenebrionidae dominates the arid habitats of the world, from deserts to coastal dunes (Fallaci et al. 1997). Members of this family play an important role in the food chain of sandy littoral systems since they contribute substantially to the consumption of 
beach debris (Colombini et al. 1994). In view of their limited dispersal capacity and their high habitat specificity, darkling beetles also exhibit a noteworthy degree of endemicity, as reported in several studies, including the ones by Contreras-Diaz et al. (2003) for tenebrionid species from the Canary Islands and by Fattorini and Leo (2000a) for the Aegean Islands.

The tenebrionid beetles Phaleria bimaculata and $P$. acuminata belong to a speciose and a widely distributed psammophilous genus; $P$. bimaculata (Linnaeus, 1767) has a wide Mediterranean distribution (Löbl and Smetana 2008) with morphologically distinct populations that have been often described as new taxa of doubtful taxonomical meaning (e.g., Canzoneri 1968; Marcuzzi 1996; de Jong 2010). The congener $P$. acuminata Küster, 1852 is distributed along the sandy coastlines of the Mediterranean (Löbl and Smetana 2008), Bulgaria, and the Black Sea (Dajoz 1984). Though the two species show overlapping ranges, they have not been compared using genetic and morphometric methods to date. Their genetic diversity is nearly unknown, and studies to identify molecular diagnostic characters have never been performed. Unfortunately, no phylogeny of the genus Phaleria is currently available, and there is thus no evidence supporting the sister-species relationship between $P$. acuminata and $P$. bimaculata.

The two studied species ( $P$. acuminata and P. bimaculata) have been recorded in large numbers from Maltese (Deidun et al. 2007, 2009) and Sicilian beaches (Canzoneri 1968; Aliquò and Leo 1997-1998; Fattorini and Leo 2000b; Deidun et al. 2011), while a third species, P. reveilleri Mulsant and Rey 1858, which is sometimes reported to occur in Sicily (e.g., Canzoneri 1968; but see also Aliquò and Soldati 2010), was not recorded in the frame of our surveys. $P$. bimaculata and $P$. acuminata have been rarely recorded in syntopy (e.g., Mifsud and Scupola 1998; Deidun et al. 2010), and they demonstrate slightly different eco-ethological characteristics. They seem to occupy different beach zones (Deidun et al. 2010) and have different grain-size preferences: $P$. acuminata shows a predilection for fine-sand beaches, and $P$. bimaculata prefers coarser sand (in some extreme cases, $P$. bimaculata is also found on cobble beaches, e.g., Canzoneri 1968; Gardini 1975; Minelli et al. 2002).

From a taxonomic perspective, the $P$. acuminata populations from the central Mediterranean area show a scarce differentiation, being somehow consistent and homogenous in terms of morphology of exoskeleton characters (Canzoneri 1968; Aliquò and Soldati 2010).

Conversely, the $P$. bimaculata populations occurring within the same geographical area demonstrate a high degree of polymorphism, with several populations already being recognized as distinct taxa of intra-specific rank (subspecies, “races," “nationes," cf. Canzoneri 1968), or at least described as such (Canzoneri 1968). One such example is the subspecies $P$. bimaculata marcuzzii Aliquò 1993, which was described for the Aeolian Islands (Fig. 1), with its locus typicus located on the island of Vulcano (Aliquò 1993). The P. bimaculata populations from the Aegadian Islands are also considered different from the nominal subspecies by Canzoneri (1970), but they have not been formally described as such.

The results of a geometric preliminary morphometric analysis of different $P$. bimaculata populations from the Maltese and Sicilian archipelagos, reported in Deidun et al. (2011), confirmed the high degree of inter-populations morphological variability within $P$. bimaculata from such a geographical region. The results proved to be compatible with the possible subspecific taxonomic status of the Aeolian $P$. bimaculata populations (i.e., P. bimaculata marcuzzii). In light of these results, Deidun et al. (2011) recommended the inclusion of a higher number of Phaleria populations in the geometric morphometric analyses, and the implementation of molecular techniques to test and corroborate the results of both traditional morphology and geometric morphometry analyses. Following these guidelines, the primary aims of this paper are (1) to describe the morphological and molecular diversity of the central Mediterranean populations of two widespread Phaleria species and (2) to compare the accuracy and consistency of different identification techniques, i.e., traditional morphology, molecular identification, and geometric morphometry. Finally, the study also aims (3) to gauge the putative degree of compartmentalization along close beaches through the characterization of the within-species and between-species variation of $P$. bimaculata and $P$. acuminata sampled over different spatial scales.

\section{Materials and methods}

\section{Sampling}

A total of 25 Phaleria spp. populations from sandy beaches on different central Mediterranean archipelagos (Maltese, Pelagian, Aegadian, and Aeolian ones) and on the Sicilian mainland were sampled once, over the March-October 2010 period (Fig. 1). The full list of sampled sandy beaches is given in Table 1, while Fig. 1 gives the geographical location of the sampled sites. The supralittoral zone of these beaches was sampled by means of individual pitfall traps or by means of constellations of pitfall traps, each of which consisted of five plastic cups (diameter $=7.5 \mathrm{~cm}$ ) buried with their mouth flush with the surface of the sand and connected by means of thin wooden walkways. Such walkways 


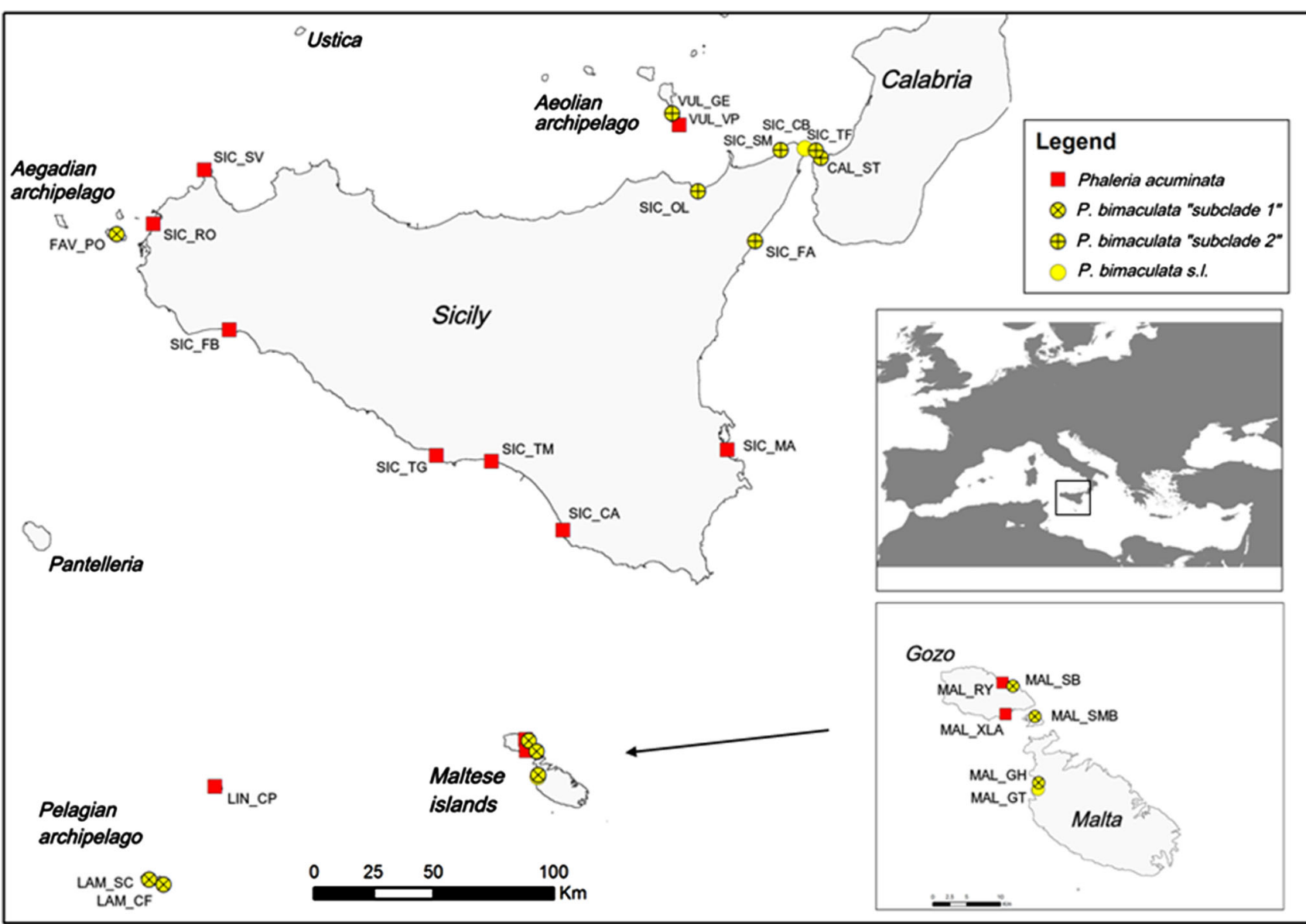

Fig. 1 Map of the studied Phaleria spp. populations. The locality codes are those reported in Table 1. The two P. bimaculata sub-clades are those highlighted by the molecular analyses

increase the efficiency of the traps as they divert any wandering animal that makes contact with the walkways into the traps (L. Chelazzi, personal communication, see Gauci et al. 2005). Where substrate type (e.g., too coarse a sediment) or beach attributes (e.g., too narrow a beach) precluded the deployment of pitfall trap constellations, individual, non-connected traps (plastic cups) were used instead. A mixture of freshwater and vinegar (3:1) was placed in each trap as an attractant, with the traps being deployed at dusk and emptied at dawn. Collected Phaleria spp. specimens were sorted out and fixed in situ in $95 \%$ ethanol.

Identification of the collected specimens was carried out under a stereomicroscope according to the morphological characteristics described by Canzoneri (1968). When necessary, selected specimens were dissected in order to study the form of the aedeagus.

DNA extraction, amplification, and sequence analyses

Prior to DNA extraction, heads and legs of selected specimens (Table 1) were soaked in double-distilled water for
2-3 h. DNA was then extracted using whole specimens and following the "DNEasy-Animal Tissue Kit" (QIAGEN) protocol.

A fragment of the cytochrome c oxidase subunit II mitochondrial gene (COII) was amplified using the primer pairs described by Contreras-Diaz et al. (2003) and the following thermal cycle: $5^{\prime}$ at $95^{\circ} \mathrm{C}$ followed by 35 cycles with $1^{\prime}$ at $95{ }^{\circ} \mathrm{C}, 1^{\prime}$ at $50{ }^{\circ} \mathrm{C}$, and $1^{\prime}$ at $72{ }^{\circ} \mathrm{C}$; a final extension of $8^{\prime}$ at $72{ }^{\circ} \mathrm{C}$ concluded the PCR. The PCR mix consisted of $17.63 \mu \mathrm{l}$ of double-distilled water, $2.5 \mu \mathrm{l}$ Buffer $10 \times, 2 \mu \mathrm{MgCl}_{2}$ solution $(25 \mathrm{mM}), 0.12 \mu \mathrm{ldNTPs}$ (20 mM), $0.25 \mu \mathrm{l}$ of each primer $(25 \mu \mathrm{M}), 0.25 \mu \mathrm{l}$ Taq polymerase $5 \mathrm{u} / \mu \mathrm{l}$, and $2 \mu \mathrm{l}$ of DNA template, for a total reaction volume of $25 \mu$ l.

After PCR, $5 \mu$ l of each PCR product was separated by electrophoresis on a $2 \%$ agarose gel at $70 \mathrm{~V}$ for $1 \mathrm{~h}$ and visualized with a UV Transilluminator. When PCR products showed a clear and single band of the correct length, they were purified using the Exo-SAP-IT kit and sequenced with an ABI 3130xL (Applied Biosystems) sequencer. The forward primer was used for direct sequencing of the PCR product, and if the sequences were not of sufficient quality, 
Table 1 List of the studied populations and of the specimens included in the molecular and morphometrical analyses

\begin{tabular}{|c|c|c|c|c|c|c|}
\hline Site code & Locality & $\begin{array}{l}\text { Coordinates } \\
\text { (WGS84) }\end{array}$ & Taxon & $\begin{array}{l}\text { \# of specimens } \\
\text { studied for the } \\
\text { elytra }\end{array}$ & $\begin{array}{l}\text { \# of specimens } \\
\text { studied for the } \\
\text { pronotum }\end{array}$ & $\begin{array}{l}\text { \# of specimens } \\
\text { included in the } \\
\text { molecular analyses }\end{array}$ \\
\hline CAL_ST & Calabria-Santa Trada & $38.242210 \mathrm{~N} ; 15.673196 \mathrm{E}$ & PB2 & 3 & 3 & 1 \\
\hline FAV_PO & Favignana-Port & $37.928888 \mathrm{~N} ; 12.325555 \mathrm{E}$ & PB1 & 10 & 10 & 2 \\
\hline LAM_CF & Lampedusa-Cala Francese & $35.495555 \mathrm{~N} ; 12.624722 \mathrm{E}$ & PB1 & 0 & 0 & 1 \\
\hline LAM_SC & Lampedusa-Spiaggia dei Conigli & $35.513055 \mathrm{~N} ; 12.557222 \mathrm{E}$ & PB1 & 15 & 14 & 1 \\
\hline LIN_CP & Linosa-Cala di Ponente & $35.867222 \mathrm{~N} ; 12.851111 \mathrm{E}$ & PA & 0 & 0 & 1 \\
\hline MAL_GH & Malta-Ghajn Tuffeha & $35.928888 \mathrm{~N} ; 14.343888 \mathrm{E}$ & PB1 & 0 & 0 & 2 \\
\hline MAL_GT & Malta-Gnejna Bay & $35.920278 \mathrm{~N} ; 14.343055 \mathrm{E}$ & PB & 15 & 13 & 0 \\
\hline MAL_RY & Gozo-Ramla beach & $36.061388 \mathrm{~N} ; 14.284166 \mathrm{E}$ & PA & 11 & 10 & 1 \\
\hline MAL_SB & Gozo-San Blas & $36.056944 \mathrm{~N} ; 14.300833 \mathrm{E}$ & PB1 & 0 & 0 & 1 \\
\hline MAL_SMB & Comino-S. Marija Bay & $36.016666 \mathrm{~N} ; 14.337222 \mathrm{E}$ & PB1 & 15 & 8 & 1 \\
\hline MAL_XLA & Gozo-Xatt 1-Ahmar & $36.019795 \mathrm{~N} ; 14.289272 \mathrm{E}$ & PA & 16 & 17 & 0 \\
\hline SIC_CA & Sicily-Camarina & $36.847222 \mathrm{~N} ; 14.452500 \mathrm{E}$ & PA & 15 & 15 & 1 \\
\hline SIC_CB & Sicily-Casa Bianca & $38.279253 \mathrm{~N} ; 15.595860 \mathrm{E}$ & $\mathrm{PB}$ & 15 & 14 & 0 \\
\hline SIC_FA & Sicily-Foce dell'Agrò & $37.931388 \mathrm{~N} ; 15.357222 \mathrm{E}$ & PB2 & 4 & 4 & 1 \\
\hline SIC_FB & Sicily-Foce del Belice & $37.581388 \mathrm{~N} ; 12.870277 \mathrm{E}$ & PA & 3 & 3 & 2 \\
\hline SIC_MA & Sicily-Magnisi & $37.150138 \mathrm{~N} ; 15.223411 \mathrm{E}$ & PA & 0 & 0 & 1 \\
\hline SIC_OL & Sicily -Oliveri & $38.120000 \mathrm{~N} ; 15.086111 \mathrm{E}$ & PB2 & 15 & 15 & 2 \\
\hline SIC_RO & Sicily-Ronciglio & $37.971008 \mathrm{~N} ; 12.497649 \mathrm{E}$ & PA & 0 & 0 & 1 \\
\hline SIC_SM & Sicily-Sindaro Marina & $38.272562 \mathrm{~N} ; 15.481321 \mathrm{E}$ & PB2 & 12 & 13 & 1 \\
\hline SIC_SV & Sicily-San Vito & $38.178396 \mathrm{~N} ; 12.733155 \mathrm{E}$ & PA & 0 & 0 & 1 \\
\hline SIC_TF & Sicily-Torre Faro & $38.270733 \mathrm{~N} ; 15.648744 \mathrm{E}$ & PB2 & 9 & 9 & 1 \\
\hline SIC_TG & Sicily-Torre Gaffe & $37.122500 \mathrm{~N} ; 13.855000 \mathrm{E}$ & PA & 13 & 13 & 1 \\
\hline SIC_TM & Sicily-Torre Manfria & $37.103055 \mathrm{~N} ; 14.115277 \mathrm{E}$ & PA & 15 & 15 & 1 \\
\hline VUL_GE & Vulcano-Gelso beach & $38.368888 \mathrm{~N} ; 14.995833 \mathrm{E}$ & PA & 15 & 15 & 2 \\
\hline VUL_VP & Vulcano-Ponente beach & $38.411666 \mathrm{~N} ; 14.963611 \mathrm{E}$ & PB2 & 15 & 15 & 1 \\
\hline
\end{tabular}

PA, Phaleria acuminata; PB, P. bimaculata s.1. (no molecular data available); PB1, P. bimaculata "Southern sub-clade"; PB2, P. bimaculata "Tyrrhenian sub-clade"

the complement/reverse sequences were obtained additionally.

Chromatograms were imported and edited with Chromas Lite 2.01 (Technelysium Pty Ltd) and exported to be aligned with ClustalX (Thompson et al. 1997). The sequences were deposited in GenBank with the accession numbers (A.N.) JX982338-JX982365 (Table 2). A COII sequence of the tenebrionid beetle Nesotes helleri (Reitter 1922) was downloaded from GenBank (A.N.: AJ299304.1) to be used as out-group in the molecular analyses.

Bayesian (BA) and maximum likelihood (ML) analyses were performed as implemented in MrBayes 3.1.2 (Huelsenbeck and Ronquist 2001) and PhyMl v.3 (Guindon et al. 2010). For both analyses, the best evolutionary model for each dataset was selected using mrModeltest (Nylander 2004). According to the Akaike Information Criterion (AIC), the best-fit model for ML analysis proved to be a general time-reversible plus invariant sites model $(\mathrm{GTR}+\mathrm{I})$; as a measure of branch support, bootstrap values were calculated with 1,000 replicates in the ML trees. BA analysis was carried out with the following settings: ngen $=500,000$ nchains $=4$ nrun $=2$ sample $=500$ temp $=0.1 ;$ default priors; the best BA parameters selected by AIC were the following: Prset statefreqpr $=$ dirichlet $\quad(1,1,1,1)$; Lset $n s t=6$ rate$\mathrm{s}=$ propinv. The node stability of BA trees was evaluated from their posterior probabilities.

Geometric morphometrics

The study involved the use of the geometric morphometrics technique, which is nowadays a standard protocol in morphological research. The geometric morphometrics techniques (Bookstein 1991; Rohlf and Marcus 1993; Adams et al. 2004; Zelditch et al. 2004; Viscosi and Cardini 2011) were used to quantify and analyze the inter- and intraspecific differentiation in the shape of two external anatomical structures in the collected Phaleria spp. specimens, 
Table 2 GenBank accession numbers of the studied specimens
PA, Phaleria acuminata; PB1, $P$. bimaculata "Southern subclade"; PB2, P. bimaculata "Tyrrhenian sub-clade"

\begin{tabular}{|c|c|c|c|}
\hline Site code & Specimen code & Taxon & GenBank accession numbers \\
\hline CAL_ST & CAL_ST_281 & PB2 & JX982340 \\
\hline FAV_PO & FAV_PO_1 & PB1 & JX982350 \\
\hline FAV_PO & FAV_PO_2 & PB1 & JX982351 \\
\hline LAM_CF & LAM_CF_284 & PB1 & JX982361 \\
\hline LAM_SC & LAM_SC_256 & PB1 & JX982364 \\
\hline LIN_CP & LIN_CP_285 & PA & JX982354 \\
\hline MAL_GH & MAL_GH_11 & PB1 & JX982360 \\
\hline MAL_GH & MAL_GH_6 & PB1 & JX982344 \\
\hline MAL_RY & MAL_RY_283 & PA & JX982341 \\
\hline MAL_SB & MAL_SB_188 & PB1 & JX982342 \\
\hline MAL_SMB & MAL_SMB_308 & PB1 & JX982343 \\
\hline SIC_CA & SIC_CA_8 & PA & JX982345 \\
\hline SIC_CB & SIC_CB_307 & PB2 & JX982362 \\
\hline SIC_FA & SIC_FA_1 & PB2 & JX982363 \\
\hline SIC_FB & SIC_FB_1 & PA & JX982348 \\
\hline SIC_FB & SIC_FB_5 & PA & JX982349 \\
\hline SIC_MA & SIC_MA_305 & PA & JX982356 \\
\hline SIC_OL & SIC_OL_1 & PB2 & JX982358 \\
\hline SIC_OL & SIC_OL_253 & PB2 & JX982359 \\
\hline SIC_RO & SIC_RO_304 & PA & JX982355 \\
\hline SIC_SM & SIC_SM_306 & PB2 & JX982365 \\
\hline SIC_SV & SIC_SV_303 & PA & JX982353 \\
\hline SIC_TF & SIC_TF_282 & PB2 & JX982347 \\
\hline SIC_TG & SIC_TG_2 & PA & JX982352 \\
\hline SIC_TM & SIC_TM_5 & PA & JX982346 \\
\hline VUL_GE & VUL_GE_1 & PA & JX982357 \\
\hline VUL_GE & VUL_GE_309 & PA & JX982339 \\
\hline VUL_VP & VUL_VP_2 & PB2 & JX982338 \\
\hline
\end{tabular}

i.e., the pronotum and the elytra. Statistical variations in the shape of the pronotum and of the right elytra in different $P$. bimaculata and $P$. acuminata individuals were analyzed using multivariate statistics.

The pattern of morphological body-shape variation was analyzed in eighteen Phaleria spp. populations. Analyses were performed on 206 pronota and 216 elytra (Table 1). Head and limbs from sampled specimens were dissected to be used for the DNA extraction and subsequent molecular analyses.

After dissection, the remaining body parts were mounted on an entomological card. The specimens were positioned along a horizontal plane; for each individual, only the right portion of the body was examined, with the aim of removing any possible bias caused by bilateral asymmetry. Dorsal images were digitized using a Leica D-LUX $3 \ll$ LMS $\gg$ camera mounted on the optical stereomicroscope Wild M3.
The digital images of the pronotum and the elytra were processed separately with mAKEfAN6 (Sheets 2003). For each body structure, the landmarks and semi-landmarks configuration was identified following criteria of homology (Bookstein 1991). Within the pronotum, the Cartesian $\mathrm{x}, \mathrm{y}$ coordinates of four landmarks and six semi-landmarks were recorded. In the elytra, the Cartesian $\mathrm{x}, \mathrm{y}$ coordinates of four landmarks and twelve semi-landmarks were recorded.

The position of the pronotum landmarks and semilandmarks adopted in this study is shown in Fig. 2a, while the position of elytra landmarks and semi-landmarks is shown in Fig. 2 b.

The bidimensional coordinates of the anatomical landmarks and semi-landmarks on the outline of the dorsal view of the pronotum and the right elytra were collected and digitized by means of TPSDIG2 (Rohlf 2004). In order to better perform statistical analysis, the landmarks and semi-landmarks were successively recognized with TPSUTIL 1.45 (Rohlf 2008). 
Fig. 2 Landmarks and semilandmarks positioning on Phaleria specimens. a Four landmarks $(1,3,9$, and 10) and six semi-landmarks for pronotum $(2,4,5,6,7$, and 8); b four landmarks $(1,2,3$, and 16) and twelve semi-landmarks $(4,5,6,7,8,9,10,11,12,13$, 14 , and 15) on the right elytra. The landmarks were digitized on half of each structure to remove the variability introduced by the possible asymmetry

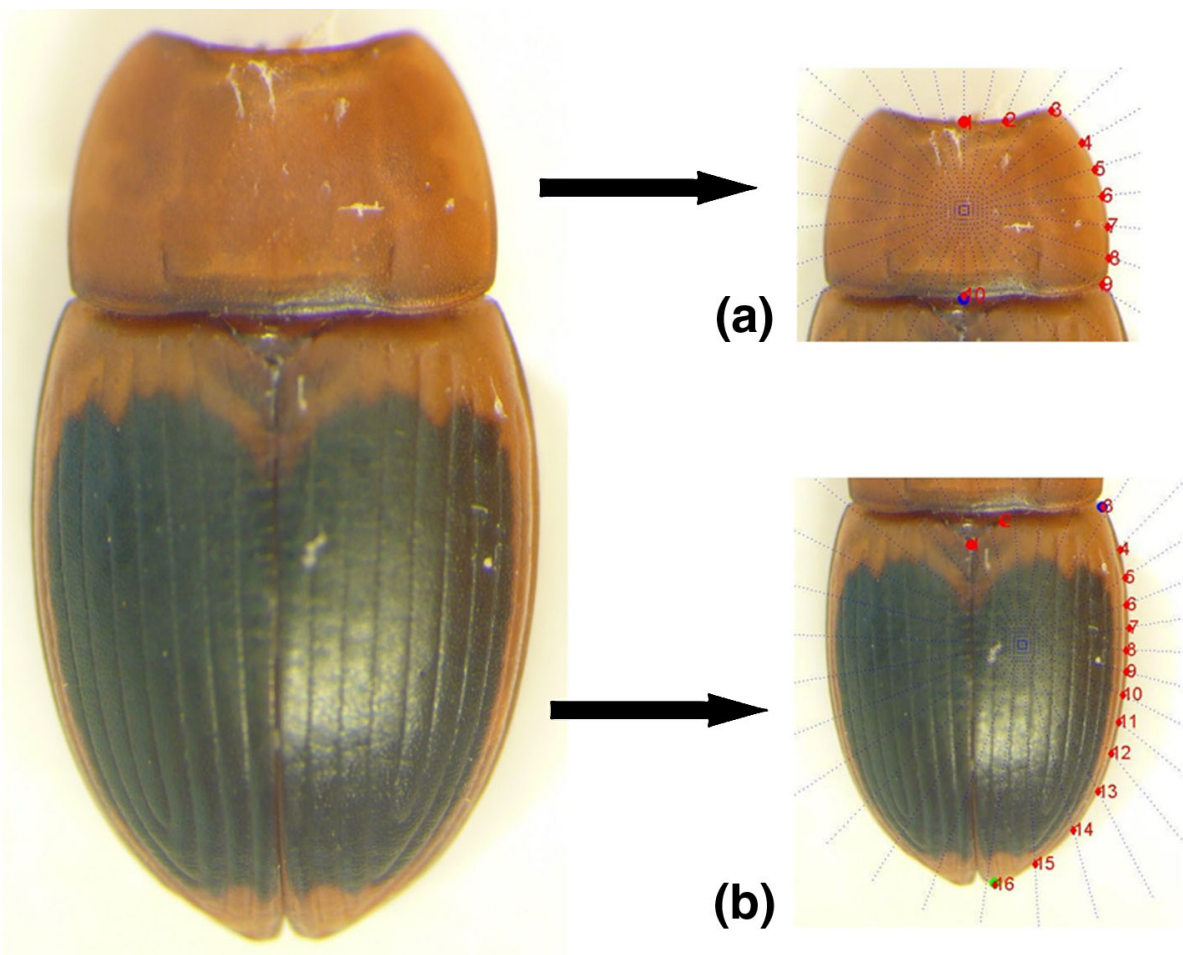

The resulting coordinates were subjected to a generalized procrustes analysis (GPA), which removes all the information that is unrelated to shape (Rohlf and Slice 1990). The perpendicular projection or minimum procrustes distance criterion, in this study, was used to align the semi-landmarks along their respective curves. In this case, the coordinates of the outlines were slid along a tangential direction, in order to minimize the procrustes distance between the specimen and a reference.

For the comparison of the configurations of landmarks and semi-landmarks, the relative warps method (RWM) was used (Bookstein 1991; Rohlf 1993). The relative warps are principal component vectors of the partial warps, variables generated for thin-plate spline transformations (Bookstein 1989), and were used to describe the major trends in shape variation among specimens within the sample (Rohlf 1993, 1996). Thin-plate spline deformation grids were generated to facilitate description of shape variation. The analyses were performed by means of Relative Warps 1.39 (Rohlf 2004).

The Discriminant function

Discriminant function analysis (DFA) of the morphometric data was performed using mORPHOj 1.01 (Klingenberg 2011) and used in order to test the separation of the morphotypes attributable to the two species (Zelditch et al. 2004). The DFA examines the separation between two groups of observations, known a priori. The procedure carries out a leave-one-out cross-validation to assess the reliability of classification. The analysis automatically includes a parametric $T$-square test for the difference between group means.

\section{Results}

The ML and BA molecular analyses gave congruent results, which are summarized in Fig. 3. The BA tree, rooted on the tenebrionid species Nesotes helleri, singles out two well-supported clades, corresponding to the populations ascribed to $P$. acuminata and $P$. bimaculata based on morphological analyses. The only exception is the sample from Vulcano-Gelso (VUL_GE), which was identified as P. bimaculata marcuzzii by Deidun et al. (2011), but which clustered with the $P$. acuminata clade in the present study.

The $P$. acuminata clade is poorly structured, as the populations are rather homogeneous, both on the Sicilian mainland and on the circum-Sicilian islands. Conversely, it is possible to distinguish two supported sub-clades (hereby reported as the "Tyrrhenian" and the "Southern" subclades, respectively) within the $P$. bimaculata clade (Fig. 3), although the molecular distance between them is rather low (Table 3).

As stressed in the RWM plot (Fig. 4), there are noteworthy inter-specific differences in the shape of the pronotum and the elytra. When compared with those of 
Fig. 3 a Phylogeographic reconstruction of Phaleria spp. from central Mediterranean area based on a 660-bp-long fragment of the mitochondrial gene COII. The tree topologies based on BA and ML analyses are congruent at the higher nodes. Support at nodes is represented as "BA posterior probability/ML bootstrap." The node support for ML tree is based on 1,000 bootstrap replicates. ML analysis is based on the GTR + I evolutionary model. See Tables 1 and 3 for the locality codes and GenBank accession numbers. b An the genetic diversity outlined in Phaleria spp. The direction of the two branches into which the MAW bifurcates and of the AIS through the Sicily Strait are evidenced, according to Malanotte-Rizzoli et al. 1997; Millot 1999; Pinardi et al. 2005 iconographic representation of

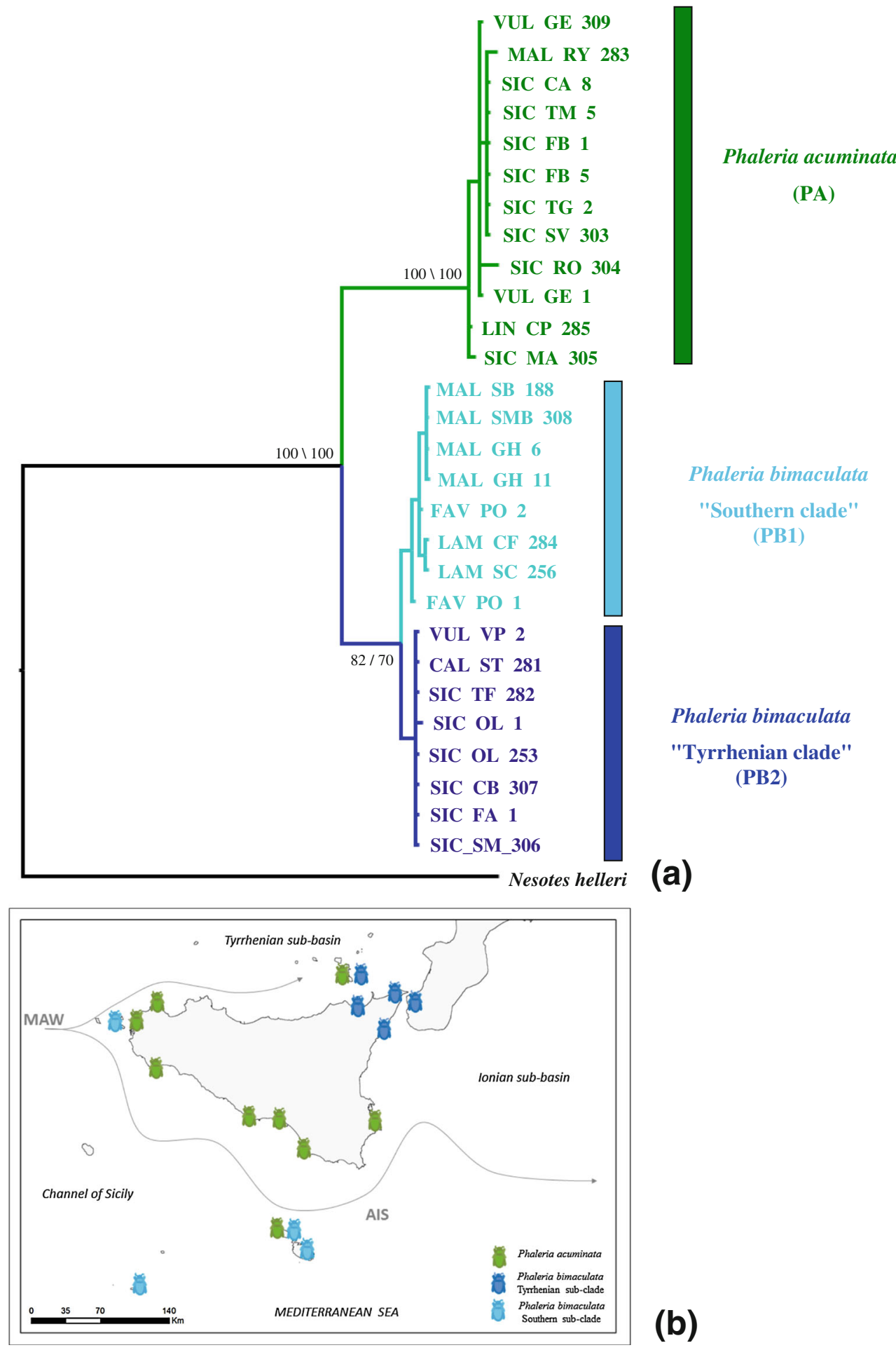

$P$. bimaculata, $P$. acuminata elytra are more elongated and elliptical, and the pronotum of the latter is narrower, with a less curved margin.

DFA was carried out separately for elytra and pronotum data, imposing the grouping of the specimens according to their species and sub-clade genetic affiliation. DFA allowed to clearly distinguish $P$. acuminata from $P$. bimaculata for both elytra and pronotum (Fig. 5a, b); furthermore, based on pronotum-only data, a significant morphometric difference was detected among the populations belonging to the two molecular clades singled out for $P$. bimaculata (see Fig. 5c); conversely, no significant differences were observed when these populations were compared solely on the elytra data. The two Phaleria 
Table 3 Molecular distances among the clades and sub-clades singled out in Fig. $5 \mathrm{a}$

\begin{tabular}{|c|c|c|c|c|}
\hline & PA & PB1 & PB2 & Out. \\
\hline P. acuminata $(\mathrm{PA})$ & & 0.06 & 0.06 & 0.18 \\
\hline $\begin{array}{l}\text { P. bimaculata "Southern sub-clade" } \\
\text { (PB1) }\end{array}$ & 0.07 & & 0.01 & 0.17 \\
\hline $\begin{array}{l}\text { P. bimaculata "Tyrrhenian sub-clade" } \\
\text { (PB2) }\end{array}$ & 0.07 & 0.01 & & 0.17 \\
\hline Out-group (Nesotes helleri) & 0.27 & 0.26 & 0.26 & \\
\hline
\end{tabular}

Uncorrected p distances (above the diagonal) and distances based on the best evolutionary model selected by AIC (GTR + I, below the diagonal)

populations from the island of Vulcano, i.e., VUL_GE and VUL_PV (within the Aeolian archipelago, the locus typicus of $P$. bimaculata marcuzzii), did not cluster together in the DFA: One of them clustered within the $P$. acuminata populations, and the second one clustered within the $P$. bimaculata s.l. populations belonging to the "Tyrrhenian sub-clade."

All the pairwise comparisons performed by the DFA were highly significant $(p<0.0001)$ and the relative classifications proved to be reliable. The classification table (Table 4) shows the percentage correct attributions to the a priori molecularly identified groups (i.e., PA: P. acuminata vs. PB: P. bimaculata; PB1: P. bimaculata "Southern subclade" vs. PB2: $P$. bimaculata "Tyrrhenian sub-clade").

\section{Discussion}

There is a perfect agreement between geometric morphometry and molecular analyses in assigning the studied Phaleria populations to the species $P$. acuminata or $P$. bimaculata s.l. Previously, a good agreement was observed also with the identification results from the conventional morphological investigation, with the only exception being the population from Vulcano-Gelso (VUL_GE), which was assigned to $P$. bimaculata marcuzzii by Deidun et al. (2011), while it is ascribed to $P$. acuminate in the present study on the bases of both morphometric and molecular evidence. Upon a careful morphological reanalysis, in fact, the Vulcano-Gelso population proved to belong to $P$. bimaculata s.l., thus providing evidence that the original identification of the same samples as reported by Deidun et al. (2011) was erroneous. The taxonomical value and the species-level discriminatory power of the geometric morphometrics analyses in Tenebrionidae, already demonstrated for different genera (e.g., Taravati et al. 2009; PericMataruga et al. 2008), are thus also confirmed for the genus Phaleria, where the elytra and the pronotum proved to be
Fig. 4 Scatterplots of two first relative warps scores obtained from the RWM of the shape of two external morphological structures. Plots show deformation grids relative to each axis; a pronotum: RW1 + RW2 accounted for a total of $79.11 \%$; b elytra: for a total of $71.01 \%$

consistent discriminant character among the studied species (Fig. 5a, b; Table 4).

The morphogenetic approach allowed us to further discriminate two well-characterized sub-clades within $P$. $b i$ maculata; these are geographically segregated, and they are separated by modest molecular distances (Table 3 ) and by the pronotum morphometry (Fig. 4c). One of these groups includes all the $P$. bimaculata populations sampled along the Strait of Sicily, from the Maltese archipelago to the Pelagian and the Aegadian archipelago (the "Southern subclade"), and the other one includes all the populations from the northeastern Sicilian coast, Vulcano island (Aeolian archipelago), and southernmost Italian mainland (the "Tyrrhenian sub-clade") (Fig. 3). This second group thus includes also the $P$. bimaculata populations currently ascribed to the subspecies $P$. bimaculata marcuzzii.

At the current state of knowledge, both the mutually exclusive hypotheses that (1) P. bimaculata marcuzzii is a valid subspecies with a wider distribution than previously thought, i.e., extending over the entire Aeolian archipelago and the southeastern Tyrrhenian coasts, and that (2) $P$. bimaculata marcuzzii is in fact a junior synonym of another $P$. bimaculata subspecies, are equally plausible and deserve further investigation. A future broader sampling protocol, which includes the topotypical populations of the presumptive subspecies and different "forms" of $P$. $b i$ maculata, is needed in order to check whether these alleged taxa of infra-specific rank coincide with well-defined molecular lineages.

Tenebrionid beetles lack a planktonic larval stage; however, the processes of water transport and rafting (passive dispersal through floating debris) between islands, described already for species like the oniscid isopod genus Idotea (ClarkinE et al. 2012), cannot be a priori dismissed (Fattorini 2002). Though other species inhabiting sandy beaches and exhibiting passive dispersal patterns, such as talitrid amphipods, show a population genetic structure shaped by the surface circulation of water masses (Pavesi et al. 2012), the geographical segregation of the two $P$. bimaculata sub-clades is not consistent with the prevailing pattern of surface currents within the central Mediterranean. The modified Atlantic water (MAW) stream bifurcates into two major streams just off the westernmost tip of Sicily (Fig. 3b), with one stream meandering along the northern coast of Sicily, in the southern Tyrrhenian, and one stream proceeding in a southeastern fashion, just south of Adventure Bank, in the Strait of Sicily (Malanotte-Rizzoli et al. 
(a)

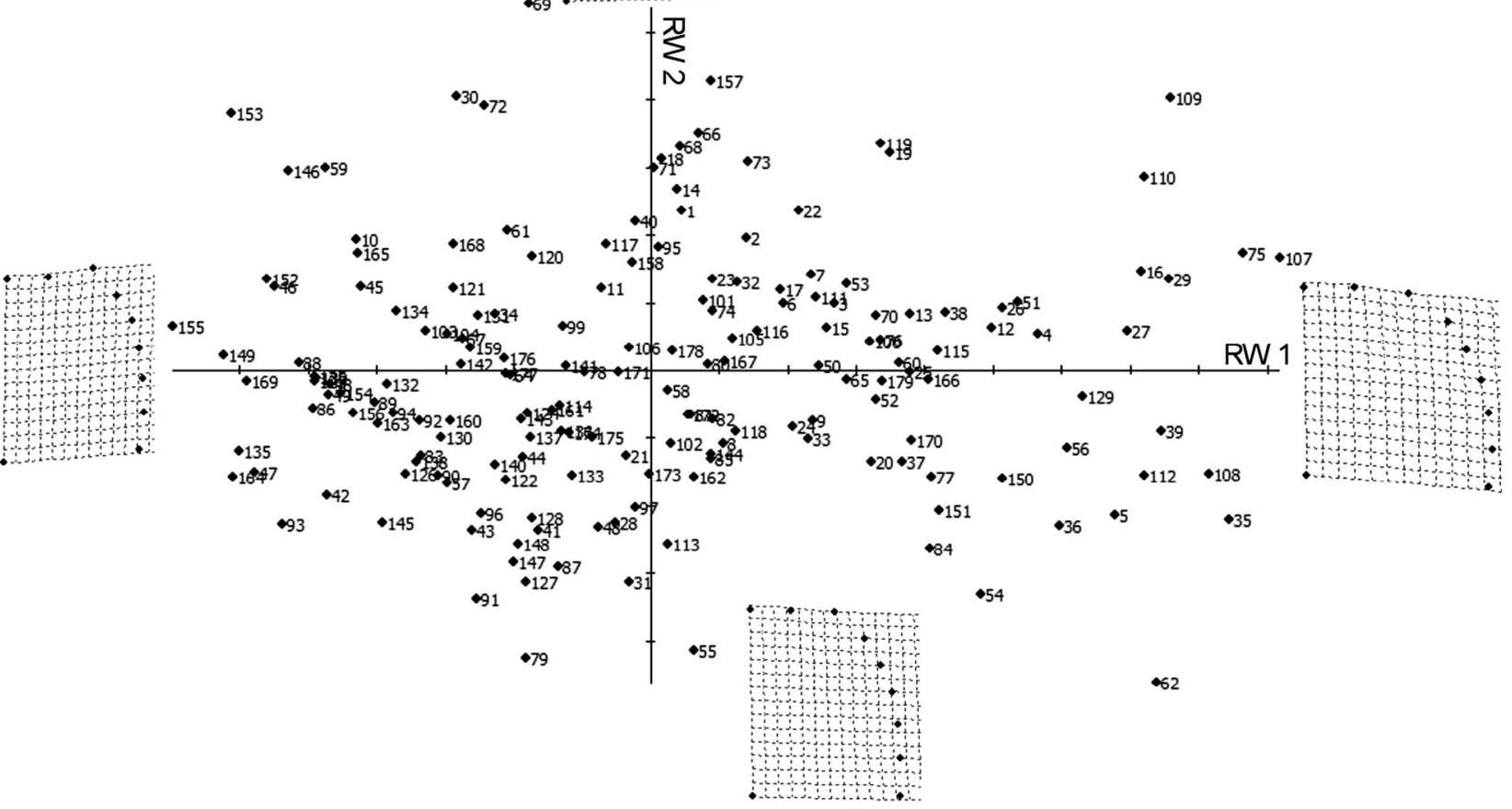

(b)

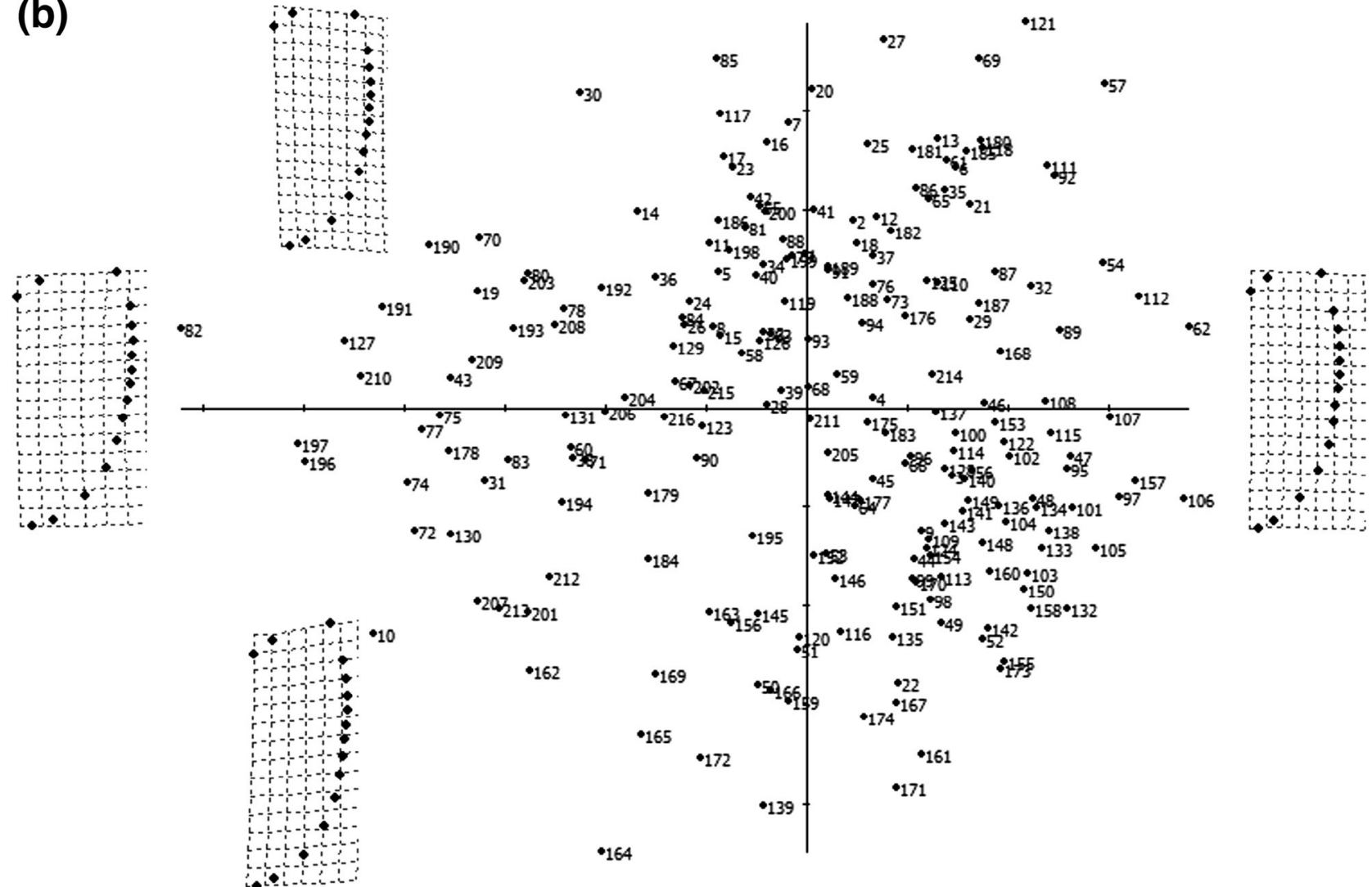



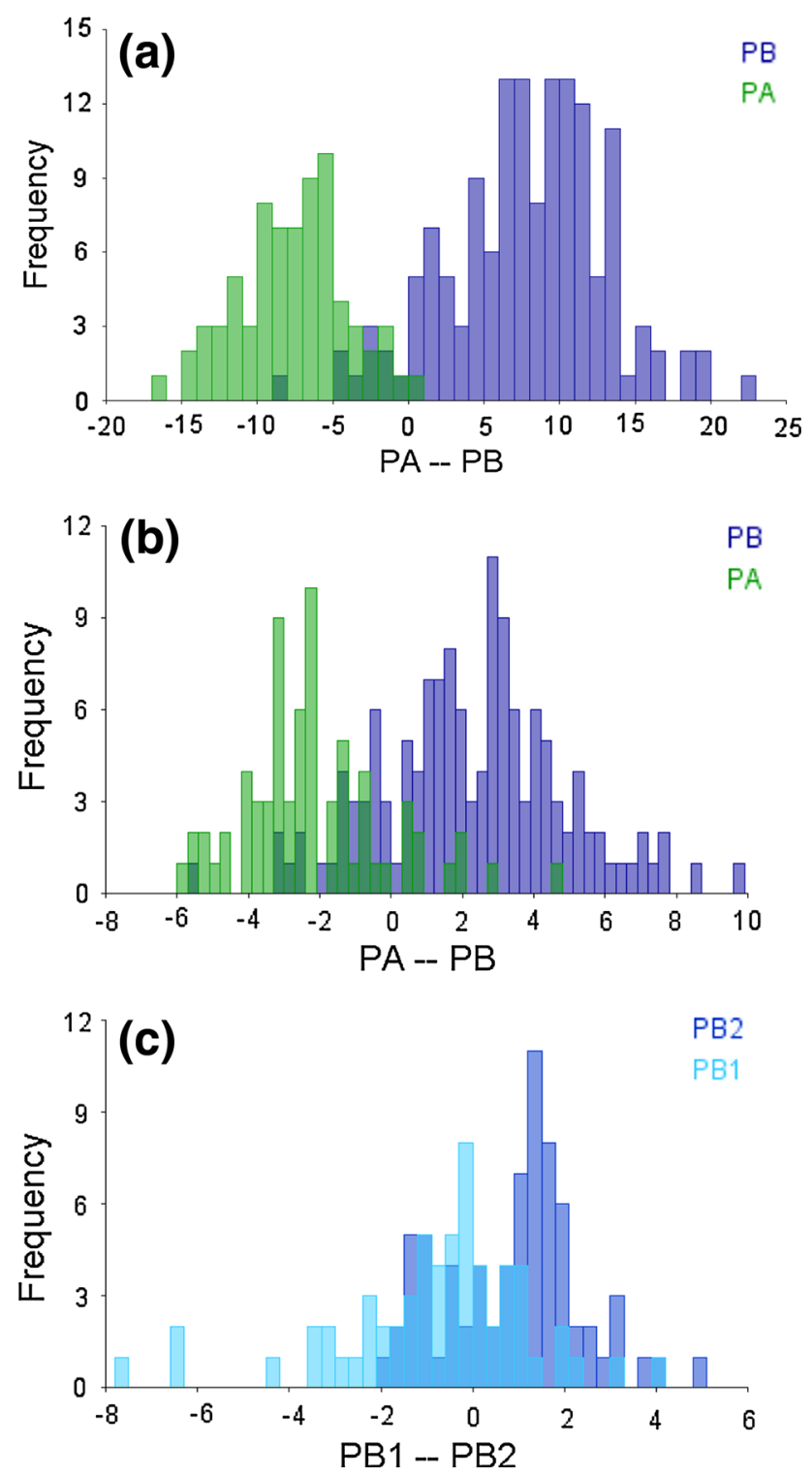

Fig. 5 Discriminant function analysis between $P$. acuminata (PA) and $P$. bimaculata (PB): a elytra, b pronotum; and discriminant function analysis between the "Southern sub-clade" (PB1) and the "Tyrrhenian sub-clade" (PB2) within P. bimaculata: c pronotum

1997; Millot 1999; Pinardi et al. 2005). The Maltese populations and the Aegadian ones are thus hydrodynamically linked by virtue of the MAW and of the Atlantic Ionic Stream (AIS) meandering their way through the Sicily Strait in a southeasterly direction. However, against such a hydrodynamic regime, gene flow should also be maintained between the Aegadian and the Tyrrhenian localities thanks to the northern stream of the MAW; however, this is incongruent with results emerging from the current study.

At a finer geographical scale, previous ecological studies on Maltese sandy beaches (e.g., Deidun and Schembri 2008; Gauci et al. 2005) have commented on the pocket nature of the same beaches surveyed, i.e., beaches that are
Table 4 Percentages of correct classification using all shape or only "size-corrected" shape in DFAs, based on the leave-one-out crossvalidation procedure

\begin{tabular}{lcc}
\hline All shape & & \\
\hline Pronotum & PA (\%) & PB $(\%)$ \\
& 88.7 & 11.3 \\
PA & 16.3 & 83.7 \\
PB & PB1 & PB2 \\
& 80.6 & 19.4 \\
PB1 & 23.3 & 73.7 \\
PB2 & & \\
Elytra & PA & PB \\
& 100 & 0 \\
PA & 4.9 & 95.1 \\
PB & PB
\end{tabular}

PA, Phaleria acuminate; PB, P. bimaculata; PB1, P. bimaculata "Southern sub-clade"; PB2, P. bimaculata "Tyrrhenian sub-clade"

headland delineated. Such a geomorphology thwarts longdistance longshore transport of sediment and propagules between adjacent or close beaches, translating in semiisolated macrobenthic assemblages (Deidun et al. 2003; Deidun and Schembri 2008). However, results from the present study do not support this hypothesis, since Phaleria spp. specimens collected from adjacent Maltese pocket beaches belonged either to different species or to the same $P$. bimaculata sub-clade. In order to further test the actual level of compartmentalization of the studied coastal environments, the realization of a broader comparative study involving diverse molecular markers and taxa with different dispersal capacities is thus advisable.

The exploration and definition of character diagnostics assume a fundamental role in biological conservation; it is noteworthy to point out that in Australia, the Mediterranean $P$. bimaculata has been accidentally introduced in the vicinity of Melbourne (Doyen et al. 1989); in such cases, the availability of sound identification methods, as the ones described in this paper, is of pivotal importance for an early recognition of the biological invasions, which otherwise might be overlooked and thus inadequately managed. Molecular techniques are known to be extremely effective in order to unveil these "cryptic invasions" (e.g., Marrone et al. 2011, and references therein), and the geometric morphometry proves to be an extremely promising costeffective alternative.

\section{References}

Adams DC, Rohlf FJ, Slice D (2004) Geometric morphometrics: ten years of progress following the 'revolution'. Ital J Zool 71:5-16 
Aliquò V(1993) Dati nuovi e riassuntivi sui coleotteri Tenebrionidi delle isole circumsiciliane (Coleoptera: Tenebrionidae). Naturalista sicil, Palermo 17:p 111-125

Aliquò V, Leo P (1997-1998) I coleotteri tenebrionidi della regione iblea (Sicilia sudorientale). Atti e Memorie dell'Ente Fauna Siciliana vol.V: $49-84$

AliquòV Soldati F (2010) Coleotteri Tenebrionidi di Sicilia (Insecta: Coleoptera Tenebrionidae). Monografie Naturalistiche, 1. Edizioni Danaus, Palermo, p 176

Bookstein FL (1989) Principal warps: thin-plate splines and the decomposition of deformations. IEEE Trans Pattern Anal Mach Intell 11:567-585

Bookstein FL (1991) Morphometric tools for Landmark data: geometry and biology. Biology Cambridge University Press, Cambridge

Canzoneri S (1968) Materiali per una monografia delle Phaleria del sottogenere Phaleria Latr. Memorie della Società Entomologica Italiana 47:117-167

Canzoneri S (1970) I Tenebrionidi delle Isole Egadi. Boll Museo civ St nat Verona 18:55-89

ClarkinE Maggs CA, Arnott A, Briggs S, Houghton JDR (2012) The colonization of macroalgal rafts by the genus Idotea (subphylum Crustacea; order Isopoda): an active or passive process? J Mar Biol Ass UK 92:1273-1282

Colombini I, Chelazzi L, Fallaci M, Palesse L (1994) Zonation and surface activity of some Tenebrionid beetles living on a Mediterranean sandy beach. J Arid Environ 28:215-230

Contreras-Diaz HG, Moya O, Oromi P, Juan C (2003) Phylogeography of the endangered darkling beetle species of Pimelia endemic to Gran Canaria (Canary Islands). Mol Ecol $12: 2131-2143$

Dajoz R (1984) Tenebrionidae européens noveaux ou peu connus. Cahiers du Naturaliste 39:89-92

de Jong YSDM (ed) (2010) Fauna Europaea version 2.3. Web Service available online at http://www.faunaeur.org

Deidun A, Schembri PJ (2008) Assessing inter-beach differences in semi-terrestrial arthropod assemblages on Maltese pocket sandy beaches (Central Mediterranean). Mar Ecol 29:108-117

Deidun A, Azzopardi M, Saliba S, Schembri PJ (2003) Low faunal diversity on Maltese sandy beaches: fact or artefact? Est Coast Shelf Sci 58:83-92

Deidun A, Saliba S, Schembri PJ (2007) Banquette faunal assemblages from groomed and ungroomed beaches in the Maltese Islands. In: Proceedings of the CIESM 38th congress, Istanbul, p 456

Deidun A, Saliba S, Schembri PJ (2009) Considerations on the ecological role of wrack accumulations on sandy beaches in the Maltese Islands and recommendations for their conservation management. J Coast Res (SI). In: Proceedings of the 10th international coastal symposium, vol 56. Portugal, pp 410-414

Deidun A, Pawley A, Schembri PJ (2010) Distribution and biology of two sympatric Phaleria (Coleoptera: Tenebrionidae) species on Maltese sandy beaches. In: Proceedings of the 39th CIESM Congress, Venice, Italy, p. 737

Deidun A, Marrone F, Sparacio I, Arculeo M, Curatolo T, Sciberras A, Sciberras J, Lo Brutto S (2011) New morphological, morphometric and distribution data on Phaleria bimaculata (Linnaeus, 1767) (Coleoptera: Tenebrionidae) from the islands and archipelagos of the Central Mediterranean area. Bull Insect 64:215-222

Doyen JT, Matthews EG, Lawrence JF (1989) Classification and annotated checklist of the Australian genera of Tenebrionidae (Coleoptera). Invertebr Syst 3(3):229-260

Fallaci M, Colombini I, Palesse L, Chelazzi L (1997) Spatial and temporal strategies in relation to environmental constraints of four tenebrionids inhabiting a Mediterranean coastal dune system. J Arid Environ 37:45-64

Fattorini S (2002) A comparison of relict versus dynamic models for tenebrionid beetles (Coleoptera: Tenebrionidae) of Aegean Islands (Greece). Belgian J Zool 132:55-64

Fattorini S, Leo P (2000a) Levels of endemism in the Aegean tenebrionids (Coleoptera, Tenebrionidae). Biogeographia Lav Soc ital Biogeogr 21:429-440

Fattorini S, Leo P (2000b) Darkling beetles from Mediterranean minor islands: new records and biogeographical notes. Boll Soc Entom ital 132:205-217

Gardini G (1975) Materiali per lo studio dei Tenebrionidi dell'Arcipelago Toscano (Col. Heteromera). Lav Soc ital Biogeogr 5:637-723

Gauci M, Deidun A, Schembri PJ (2005) Faunistic diversity of Maltese pocket sandy and shingle beaches: are these of conservation value? Oceanologia 27:219-241

Guindon S, Dufayard JF, Lefort V, Anisimova M, Hordijk W, Gascuel O (2010) New algorithms and methods to estimate maximum-likelihood phylogenies: assessing the performance of phyml 3.0. Syst Bio 59:307-21

Huelsenbeck JE, Ronquist F (2001) MrBayes: BAYESIAN inference of phylogeny. Biometrics 17:754-755

Klingenberg CP (2011) MORPHOJ: an integrated software package for geometric Morphometrics. Mol Ecol Resour 11:353-357

Lo Brutto S, Arculeo M, Grant WS (2011) Climate change and population genetic structure of marine species. Chem Ecol 27:107-119

Löbl I, Smetana A (eds) (2008) Catalogue of Palaearctic Coleoptera, vol 5. Tenebrionoidea. Apollo Books, Stenstrup, p 669

Malanotte-Rizzoli P, Manca BB, D'Alcala MR, Theocharis A, Bergamasco A, Bregant D, Budillon G, Civitarese G, Georgopoulos D, Michelato A, Sansone E, Scarazzato P, Souvermezoglou E (1997) A synthesis of the Ionian hydrography, circulation and water mass pathways during POEM-phase I. Progr Oceanogr 39:153-204

Marcuzzi G (1996) Il melanismo nel genere Phaleria Latreille (Insecta, Coleoptera, Tenebrionidae). Bollettino della Accademia Gioenia di Scienze naturali, Catania 351:9-13

Marrone F, Lo Brutto S, Arculeo M (2011) Cryptic invasion in Southern Europe: the case of Ferrissia fragilis (Pulmonata: Ancylidae) Mediterranean populations. Biologia 66:484-490

Mifsud D, Scupola A (1998) The Tenebrionidae (Coleoptera) of the Maltese Islands (Central Mediterranean). Annali del Museo Civico di Storia Naturale "G. Doria" 9:191-229

Millot C (1999) Circulation in the Western Mediterranean Sea. J Mar Syst 20:423-442

Minelli A, Chemini C, Argano R, Ruffo S (2002) La fauna in Italia. Touring Editore. Milano e Ministero dell'Ambiente e della Tutela del Territorio, Roma, p 448

Nylander JAA (2004) MrModeltest v2. Evolutionary Biology Centre, Uppsala University, Program distributed by the author

Pavesi L, Deidun A, De Matthaeis E, Tiedemann R, Ketmaier V (2012) Mitochondrial DNA and microsatellites reveal significant divergence in the beachflea Orchestia montagui (Talitridae: Amphipoda). Aquat Sci 74:587-596

Perić-Mataruga V, ProlićZ Nenadović V, Vlahović M, Mrdaković M (2008) The effect of a static magnetic field on the morphometric characteristics of neurosecretory neurons and corpora allata in the pupae of yellow mealworm Tenebrio molitor(Tenebrionidae). Int J RadiatBiol 84:1-8

Pinardi N, Arneri E, Crise A, Ravaioli M, Zavatarelli M (2005) The physical, sedimentary and ecological structure and variability of shelf areas in the Mediterranean Sea. In: Robinson AR, Brink KH (eds) The Sea vol. 14, chapter 32. Cambridge, Harvard University Press, pp 1243-1330 
Rohlf FJ (1993) Relative warp analysis and an example of its application to mosquito wings. In Contribution to Morphometrics. In: Marcus F, Bello E, García-Valdecasas A (eds) Contributions to morphometrics. Monografías del Museo Nacional de Ciencias Naturales, 8, Madrid, p 132-159

Rohlf FJ (1996) Morphometric spaces, shape components, and the effects of linear transformations. In:Marcus LF, Corti M, Loy A, Naylor GJP, Slice DE (eds)Advances in Morphometrics Nato ASI Series. Plenum Press, New York, pp 117-129

Rohlf FJ (2004) tpsDIG 2, software available at http://life.bio.sunysb. edu/morph/

Rohlf FJ(2008) tpsUtil, software available at http://life.bio.sunysb. edu/morph/

Rohlf FJ, Marcus LF (1993) A revolution in Morphometrics. Trends Ecol Evol 8:129-132

Rohlf FJ, Slice DE (1990) Estensioni del metodo di Procuste per la sovrapposizione ottimale dei punti di riferimento. Sistematica Zoologica 39:40-59

Sarà G, Milanese M, Prusina I, Sarà A, Angel DL, Glamuzina B, Nitzan T, Freeman S, Rinaldi A, Palmeri V, Montalto V, Lo Martire M, Gianguzza P, Arizza V, Lo Brutto S, De Pirro M, Helmuth B, Murray J, De Cantis S, Williams GA (2012) The impact of climate change on Mediterranean intertidal communities: losses in coastal ecosystem integrity and services. Regional Environmental Change (in press) DOI 10.1007/ s10113-012-0360-Z

Sheets HD (2003) IMP- Integrated Morphometrics Package. Department of Physics, Canisius College, Buffalo, New York. Available at:http://www2.canisius.edu/sheets/morphsoft.html

Taravati S, Darvish J, Mirshamsi O (2009) Geometric morphometric study of two species of the psammophilous genus Erodiontes (Coleoptera: Tenebrionidae) from the Lute desert, Central Iran. Iran J Anim Biosyst 5:81-89

Thompson JD, Gibson TJ, Plewniak F, Jeanmougin F, Higgins DG (1997) The CLUSTAL_X windows interface: flexible strategies for multiple sequence alignment aided by quality analysis tools. Nucleic Acids Res 25:4876-4882

Viscosi V, Cardini A (2011) Leaves, taxonomy and geometric morphometrics: a simplified protocol for beginners. PLoS ONE 6(10): 25630

Zelditch M, Swiderski D, Sheets H, Fink W (2004) Geometric morphometrics for biologists: a primer. Elsevier Academic Press, London 